\title{
Salt-sensitive hypertension in endothelin-B receptor-deficient rats
}

\author{
Cheryl E. Gariepy, ${ }^{1,2,5}$ Takashi Ohuchi, ${ }^{1}$ S. Clay Williams, ${ }^{1,5}$ James A. Richardson,, ${ }^{3,5}$ \\ and Masashi Yanagisawa ${ }^{1,4,5}$ \\ ${ }^{1}$ Howard Hughes Medical Institute, \\ ${ }^{2}$ Department of Pediatrics, \\ ${ }^{3}$ Department of Pathology, \\ ${ }^{4}$ Department of Molecular Genetics, and \\ ${ }^{5}$ The Donald W. Reynolds Cardiovascular Clinical Research Center, University of Texas Southwestern \\ Medical Center, Dallas, Texas 75390, USA \\ Address correspondence to: Masashi Yanagisawa, Howard Hughes Medical Institute, \\ University of Texas Southwestern Medical Center, 5323 Harry Hines Boulevard, Y5.210, \\ Dallas, Texas 75390-9050, USA. Phone: (214) 648-5082; Fax: (214) 648-5068; E-mail: myanagisawa@aol.com.
}

Received for publication October 5, 1999, and accepted in revised form February 14, 2000.

\begin{abstract}
The role of the endothelin- $\mathrm{B}$ receptor $\left(\mathrm{ET}_{\mathrm{B}}\right)$ in vascular homeostasis is controversial because the receptor has both pressor and depressor effects in vivo. Spotting lethal $(s l)$ rats carry a naturally occurring deletion in the $E T_{B}$ gene that completely abrogates functional receptor expression. Rats homozygous for this mutation die shortly after birth due to congenital distal intestinal aganglionosis. Genetic rescue of $E T_{B}^{s l / s l}$ rats from this developmental defect using a dopamine--hydroxylase $(D B H)-E T_{B}$ transgene results in $\mathrm{ET}_{\mathrm{B}}$-deficient adult rats. On a sodium-deficient diet, $D B H-E T_{B} ; E T_{B}{ }^{\mathrm{s} / \mathrm{sl}}$ and $D B H$ $E T_{B} ; E T_{B}{ }^{+/+}$rats both exhibit a normal arterial blood pressure, but on a high-sodium diet, the former are severely hypertensive. We find no difference in plasma renin activity or plasma aldosterone concentration between salt-fed wild-type, $D B H-E T_{B} ; E T_{B}{ }^{+/+}$or $D B H-E T_{B} ; E T_{B}{ }^{s / s l}$ rats, and acute responses to intravenous L-NAME and indomethacin are similar between $D B H-E T_{B} ; E T_{B}{ }^{l / s l}$ and $D B H-E T_{B} ; E T_{B}{ }^{+/+}$rats. Irrespective of diet, $D B H-E T_{B} ; E T_{B}{ }^{s / s l}$ rats exhibit increased circulating ET-1, and, on a high-sodium diet, they show increased but incomplete hypotensive responses to acute treatment an $\mathrm{ET}_{\mathrm{A}}$-antagonist. Normal pressure is restored in salt-fed $D B H-E T_{B} ; E T_{B}{ }^{s / s l}$ rats when the epithelial sodium channel is blocked with amiloride. We conclude that $D B H-E T_{B} ; E T_{B}{ }^{s l / s l}$ rats are a novel single-locus genetic model of severe salt-sensitive hypertension. Our results suggest that $D B H-E T_{B} ; E T_{B}{ }^{s / s l}$ rats are hypertensive because they lack the normal tonic inhibition of the renal epithelial sodium channel.
\end{abstract}

J. Clin. Invest. 105:925-933 (2000).

\section{Introduction}

A great deal of data support a pathophysiological role for endothelins, especially in diseases of the renal and cardiovascular systems. However, the role and interaction of the 2 endothelin receptors in vivo remain unclear. The role of the endothelin- $\mathrm{B}$ receptor $\left(\mathrm{ET}_{\mathrm{B}}\right)$ in vascular homeostasis is controversial because the receptor has both pressor and depressor effects in vivo. For example, activation of $\mathrm{ET}_{\mathrm{B}}$ on vascular smooth muscle produces a pressor response through vasoconstriction, whereas activation of $\mathrm{ET}_{\mathrm{B}}$ on the vascular endothelium produces a depressor response by evoking the release of the endothelium-derived vasodilators nitric oxide (NO) and prostacyclin. $\mathrm{ET}_{\mathrm{B}}$ on the vascular endothelium may also play a role in clearing circulating endothelin, thereby reducing its predominant endothelin-A receptor-mediated $\left(\mathrm{ET}_{\mathrm{A}^{-}}\right.$ mediated) pressor actions. Further, activation of $\mathrm{ET}_{\mathrm{B}}$ on the renal tubule epithelium can act as a depressor mechanism by promoting natriuresis and diuresis.

Originally discovered (1) as an endothelial-derived factor with powerful vasoconstricting activity, endothelin1 (ET-1) is now known to mediate a wide variety of potent physiological effects in many organ systems (2). Endothelins are a family of 21 amino acid peptides. In addition to ET-1, there are 2 other endothelin isopeptides, endothelin-2 (ET-2) and endothelin-3 (ET-3). Each endothelin is encoded by a distinct gene. Endothelin synthesis results from 2 proteolytic cleavages of preproendothelin. The first cleavage produces a biologically inactive "big endothelin." Big endothelin is then cleaved and activated by an endothelin-converting enzyme (ECE) (3). Mammals express 2 endothelin receptors, $\mathrm{ET}_{\mathrm{A}}$ and $\mathrm{ET}_{\mathrm{B}}$, each encoded by a single gene. Both receptors are $\mathrm{G}-$ protein coupled, heptahelical transmembrane receptors. They are widely expressed in a partially overlapping tissue distribution. $\mathrm{ET}_{\mathrm{A}}$ shows strongest affinity for ET-1 and is not activated by ET- 3 at physiological concentrations (4). $\mathrm{ET}_{\mathrm{B}}$ accepts all 3 ligands with equal high affinity (5). $\mathrm{ET}_{\mathrm{B}}$ activation leads to a wide variety of intracellular signal transduction events. For example, depending on the cell type, $\mathrm{ET}_{\mathrm{B}}$ activation increases intracellular calcium (1), increases nitric oxide synthase (NOS) activity $(6,7)$, activates phospholipase $C$ and phospholipase A2 $(5,8,9)$, and inhibits adenyl cyclase (10). Available evi- 
dence indicates that $\mathrm{ET}_{\mathrm{B}}$ is normally present in a wide variety of tissues in the adult rat, including many that may be involved in regulation of arterial blood pressure. Among these are the glia and neurons in regions of the brainstem involved in the central control of cardiovascular function $(11,12)$, endothelial cells and vascular smooth muscle throughout the body, the atrial and ventricular myocardium, atrioventricular conducting tissue, and coronary vasculature. $\mathrm{ET}_{\mathrm{B}}$ is also found in multiple endocrine tissues (13) and renal tubules (14).

Animals with naturally occurring or targeted mutation of $E T_{B}$ exhibit coat color spotting and distal intestinal aganglionosis because $\mathrm{ET}_{\mathrm{B}}$ plays essential roles in the normal development of epidermal melanocytes and enteric neurons (15-17). $E T_{B}$ mutations account for approximately $5 \%$ of human Hirschsprung disease (18-20). We previously reported that spotting lethal $(s l)$ rats carry a 301-bp deletion in $E T_{B}$. The deletion results in an abnormal mRNA transcript and completely abrogates functional $\mathrm{ET}_{\mathrm{B}}$ expression (16). When homozygous for this deletion $\left(E T_{B}^{s l / s l}\right)$, rats die shortly after birth due to intestinal obstruction (21). To investigate the roles of $\mathrm{ET}_{\mathrm{B}}$ in adult physiology, we undertook a tissue-specific transgenic "rescue" of the intestinal phenotype in the $(s l)$ rat. We generated transgenic rats harboring a wild-type rat $E T_{B} \mathrm{cDNA}$ whose expression is driven by the human dopamine--hydroxylase $(D B H)$ promoter. This $5.8-\mathrm{kb}$ fragment of the human $D B H$ promoter drives $E T_{B}$ expression in the neural crest-derived enteric nervous system precursors as they colonize the developing gut (22). Rats carrying this transgene were crossed with the spotting lethal rats to produce individuals that express $E T_{B}$ only under the transcriptional control of the $D B H$ promoter $\left(D B H-E T_{B} ; E T_{B}{ }^{s l} / s l\right)$. The resulting rats exhibit normal enteric nervous system development, live into adulthood, and reproduce normally (23). $\mathrm{DBH}$ $E T_{B} ; E T_{B}{ }^{s l / s l}$ adults rats express $E T_{B}$ in adrenergic tissues (such as the locus ceruleus, adrenal medulla, and sympathetic ganglia). However, these rats lack expression of $E T_{B}$ driven by the endogenous promoter.

Here we report that $D B H-E T_{B} ; E T_{B}{ }^{s l} / s l$ rats are functionally $\mathrm{ET}_{\mathrm{B}}$ deficient and are a novel single-locus genetic model of severe salt-sensitive hypertension. Our results strongly suggest that $D B H-E T_{B} ; E T_{B}{ }^{s l / s l}$ rats exhibit systemic arterial hypertension as a result of an absence of inhibition of the apical epithelial sodium channel $(\mathrm{ENaC})$ on the renal collecting duct epitheli$\mathrm{um}$. This study provides evidence that $\mathrm{ET}_{\mathrm{B}}$ plays a physiologically important role in regulation sodium excretion by the kidney.

\section{Methods}

$E T_{B}$ genotyping by PCR. Our $D B H-E T_{B} ; E T_{B}{ }^{s l} / s l$ and $D B H-$ $E T_{B} ; E T_{B}^{+/+}$rats are albino and not distinguishable by coat color. $E T_{B}$ genotyping is accomplished by PCR on DNA isolated from tail biopsy specimens obtained at 2-3 weeks of age following a previously published protocol (23). The $3^{\prime}$ primer was designed from sequence within the first intron of $E T_{B}$. The PCR reaction will not amplify the $D B H-E T_{B}$ transgene, which does not contain this intron sequence. The primers were designed to amplify across the deletion in the spotting lethal $E T_{B}$. Therefore, the wild-type product is $301 \mathrm{bp}$ longer than the spotting lethal mutant product. Both bands are amplified in a single PCR reaction and viewed on a 1.4\% agarose, ethidium bromide stained gel.

$D B H-E T_{B}$ transgene genotyping. We previously published a protocol for transgene identification and quantification (23). Briefly, we use the technique of dot-blot hybridization of genomic DNA isolated from tail biopsies. The probe is a $2.2-\mathrm{kb}$ SstII fragment from the human $D B H$ promoter cut from the transgene vector.

In situ bybridization. Sectional in situ hybridization for $E T_{B}$ mRNA in adult rat kidneys was performed exactly as described previously (24). The $E T_{B}$ probe is a 293-bp fragment corresponding to the $3^{\prime}$ end of the first exon isolated by PCR amplification. The probe was labeled with $\left[{ }^{35} \mathrm{~S}\right]-U T P$ (Amersham) using the Maxiscript in vitro translation kit (Ambion Inc., Austin, Texas, USA). The probe does not detectably cross-hybridize with $E T_{A}$, and it also does not detect the abnormal transcript produced by the $E T_{B}{ }^{s l}$ allele (23).

Femoral artery catheterization. These studies were approved by the Institutional Animal Care Research Advisory Committee at The University of Texas Southwestern Medical Center at Dallas. Catheters were placed in the right femoral artery using standard surgical techniques. For the procedure, rats were anesthetized with ketamine $(50 \mathrm{mg} / \mathrm{kg})$ and xylazine ( 9 $\mathrm{mg} / \mathrm{kg}$ ) by subcutaneous injection. The catheter was exteriorized and secured between the scapulae. The tubing was flushed with $0.1 \mathrm{~mL}$ of $500 \mathrm{U} / \mathrm{mL}$ heparin saline and occluded with a small piece of fishing line.

Blood pressure measurement. Rats were allowed to recover from catheter placement for 24 hours. The externalized arterial catheter was connected to a previously calibrated blood pressure transducer. The animal was then placed in a high-walled cage with the catheter connection balanced over a lever on a swivel device hanging above the cage. The catheter was flushed with less than $0.1 \mathrm{~mL}$ heparin saline, and pulsatile blood pressure was recorded using a MacLab paperless recording system (model 8s; AD Instruments, Milford, Massachusetts, USA). The sampling rate was $400 \mathrm{~Hz}$. Rats with arterial catheters persistently recording narrow pulse pressures $(<20$ $\mathrm{mmHg}$ ) were not further studied. Rats were allowed to acclimate to the measurement conditions for 1 hour. Baseline pressures were obtained in the second hour. Because the animals were freely moving and active, artifacts were frequently introduced into the tracing. The final values used for data analysis represent a continuous 10-minute interval selected on the basis of (a) consistency of tracing and (b) relatively low heart rate. Pharmacologic interventions were made at the end of the baseline hour, and blood pressure monitoring generally continued for an additional hour. All blood pressure measurements/recordings and drug responses in transgenic rats 
$\left(D B H-E T B ; E T_{B}{ }^{+/+}, D B H-E T B ; E T_{B}{ }^{+/ s l}\right.$, or $\left.D B H-E T B ; E T_{B}{ }^{s l / s l}\right)$ were done in a genotype-blinded fashion. Blood pressures were measured only in male rats and, except where specifically indicated, all rats were $8-10$ weeks old.

Blood sample collection. After blood pressure measurement was complete, blood samples were obtained through the catheter without disturbing the rat. All blood samples were collected between 1500 and 1800 hours.

Measurement of ET-1 concentrations. Plasma was extracted as described elsewhere (25). Measurement of immunoreactive ET-1 concentrations in plasma were made using a commercially available enzyme linked immunoassay (EIA) kit (Wako Chemicals USA Inc., Richmond, Virginia, USA). All procedures were conducted according to the manufacturer's instructions. The kit also detects ET-2, but not ET-3 or big ET-1.

Plasma renin activity and aldosterone concentration. Plasma renin activity was measured exactly as described previously (26). Briefly, blood samples were collected into prechilled syringes and rapidly transferred to ice-cold microcentrifuge tubes containing EDTA. Plasma was separated by centrifugation at $4^{\circ} \mathrm{C}$ and immediately frozen at $-80^{\circ} \mathrm{C}$. The concentration of active renin was determined by RIA measurement of angiotensin I generation from angiotensinogen. Angiotensin I was measured in samples with and without proteinase treatment. The difference reflects renin activity in the plasma sample (Endocrine Sciences, Calabasas Hills, California, USA). Aldosterone concentration was measured by RIA after solvent extraction (Endocrine Sciences).
Plasma catecholamine and corticosterone concentration. Plasma epinephrine and norepinephrine concentrations were measured by a commercially available RIA kit (American Laboratory Products Corp., Windham, New Hampshire, USA) following the manufacturer's instructions. Plasma corticosterone was measured by RIA after solvent extraction.

Dietary treatments. Rats were fed either a normal rodent $\operatorname{diet}(0.8 \% \mathrm{NaCl})$, a sodium-deficient $\operatorname{diet}(0.008 \% \mathrm{NaCl})$, or a high-sodium diet $(8 \% \mathrm{NaCl})$. All diets were purchased from Harlan Teklad Laboratory (Winfield, Iowa, USA). All rats were fed a normal diet until 5 weeks of age. The sodium-deficient or high-sodium diets were introduced at 5 weeks of age and continued for 3 weeks, except where specifically indicated, before blood pressure measurement. The high-sodium diet and sodium-deficient diets were not visually distinguishable. Blood pressure measurements/recordings were made blinded to the type of diet the rat was receiving.

Drug treatments. Where indicated, rats were treated acutely with L-NAME $(23 \mathrm{mg} / \mathrm{kg})$ and indomethacin $(5 \mathrm{mg} / \mathrm{kg})$, FR139317 (10 mg/kg), or captopril $(30 \mathrm{mg} / \mathrm{kg})$. These treatments were given intra-arterially, through the catheter used for blood pressure measurement. These medications were suspended in $\mathrm{pH}$ neutral solutions with a dosing volume of $0.5 \mu \mathrm{L} / \mathrm{g}$. Where indicated, amiloride $(3 \mathrm{mg} / \mathrm{kg})$ was given by intraperitoneal injection daily for 3 days before blood pressure measurement. Amiloride was suspended in normal saline, and the dosing volume was $1.5 \mu \mathrm{L} / \mathrm{g}$. Finally, some rats were given ET-1 $(1 \mathrm{nmol} / \mathrm{kg})$
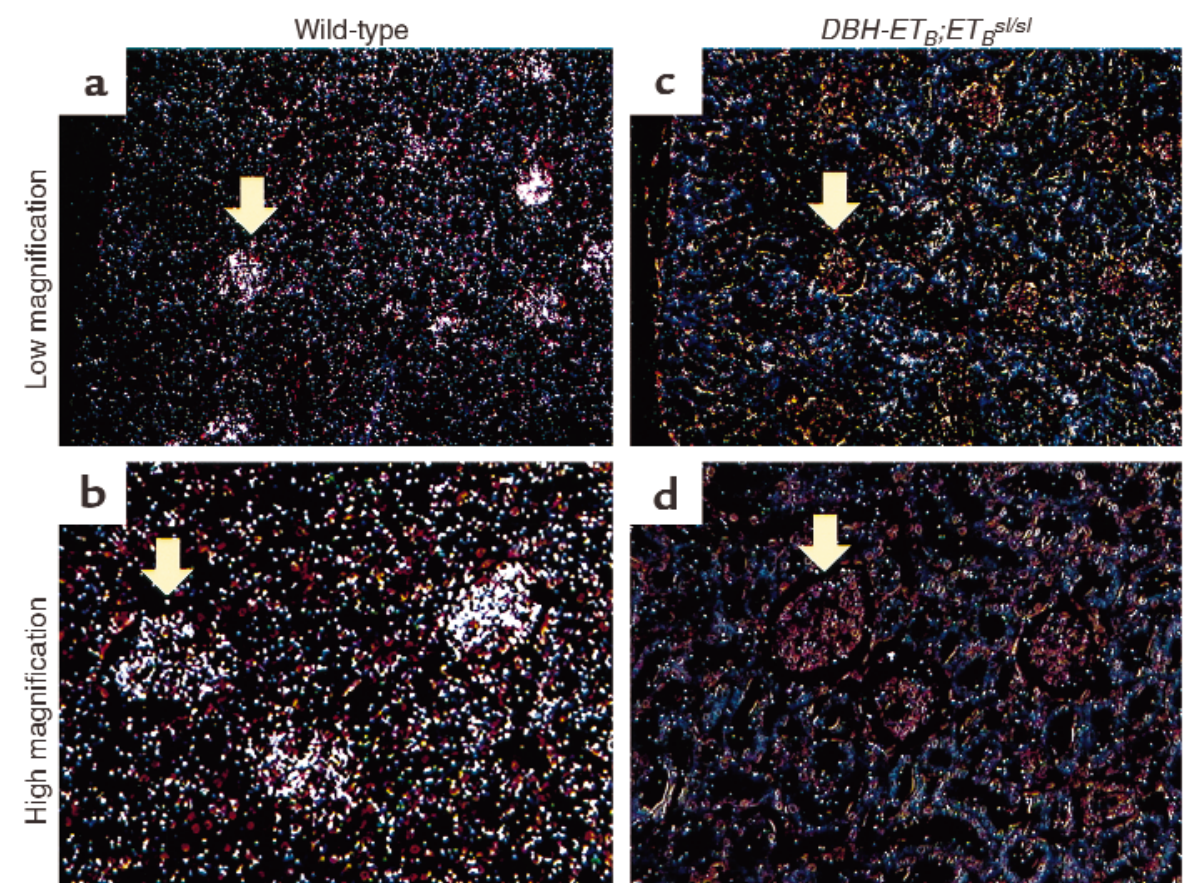

Figure 1

In situ hybridization for $E T_{B}$ mRNA in the kidney of wild-type and $D B H-E T_{B} ; E T_{B}^{s l / s l}$ adult rats. Low-power (a and $\mathbf{c}$ ) and high-power (b and $\mathbf{d}$ ) magnification of cross-sections of the renal cortex demonstrate strong hybridization signal for $E T_{B} \mathrm{mRNA}$ in the glomeruli and the associated cortical tubule and vascular structures in wild-type rats ( $\mathbf{a}$ and $\mathbf{b})$. This signal is absent in the $D B H-E T_{B} ; E T_{B}^{s / / s l}$ rats (c and d). Arrows indicate representative glomeruli. Findings were similar, though less dramatic, in the renal medulla (data not shown). 
Table 1

Serum chemistries and arterial blood gas values

\begin{tabular}{|c|c|c|c|}
\hline$E T_{B}$ genotype & $+/+$ & $+/+$ & sl/sl \\
\hline Transgene & - & + & + \\
\hline Serum chemistries & $n=3$ & $n=8$ & $n=11$ \\
\hline $\mathrm{Na}(\mathrm{meq} / \mathrm{L})$ & 140 & 141 & 138 \\
\hline $\mathrm{K}(\mathrm{meq} / \mathrm{L})$ & 4.5 & 5.0 & 5.0 \\
\hline $\mathrm{Cl}(\mathrm{mmol} / \mathrm{L})$ & 102 & 105 & 105 \\
\hline $\mathrm{CO}_{2}(\mathrm{mmol} / \mathrm{L})$ & 21 & 25 & 22 \\
\hline $\mathrm{Ca}(\mathrm{mg} / \mathrm{dL})$ & 10.2 & 10.1 & 10.2 \\
\hline Phos (mg/dL) & 9.9 & 9.3 & 7.8 \\
\hline $\mathrm{Mg}(\mathrm{meq} / \mathrm{L})$ & 1.9 & 1.6 & 3.0 \\
\hline BUN (mg/dL) & 21 & $15^{\mathrm{A}}$ & 21 \\
\hline Creatinine (mg/dL) & 0.43 & 0.40 & 0.45 \\
\hline Arterial blood gas & & $n=6$ & $n=5$ \\
\hline $\mathrm{pH}$ & & 7.49 & 7.48 \\
\hline $\mathrm{pCO}_{2}(\mathrm{mmHg})$ & & 35.7 & 35.5 \\
\hline $\mathrm{O}_{2}(\mathrm{mmHg})$ & & 102 & 98 \\
\hline Hemoglobin (g/dL) & & 14 & 13 \\
\hline
\end{tabular}

All samples were obtained from rats fed a high-sodium diet for 3 weeks. ${ }^{A} P=$ 0.01 compared to nontransgenic $E T_{B}{ }^{+/+}$, and $P=0.05$ compared to $D B H$ $E T_{B} ; E T_{B} s / s l ;$ meq, milequilivant.

through a femoral venous catheter. The injection volume was $100 \mu \mathrm{L}$. For all drug treatments, vehicle injection produced no change in arterial blood pressures.

Statistics. Data were analyzed using InStat or Prism software (Graph-Pad Software Inc., San Diego, California, USA). Comparisons between 2 groups were made using the Student's $t$ test. Three or more groups were compared using 2-way ANOVA. Mean values are reported \pm SEM, and $P$ values of less than 0.05 are considered significant.

\section{Results}

$D B H-E T_{B} ; E T_{B}{ }^{s l} / s l$ rats exhibit normal renal and cardiovascular development. Gross dissection and routine histological sectioning demonstrate no anatomic abnormalities in $D B H-E T_{B} ; E T_{B}{ }^{s l} / s l$ rats. Adult tissues examined histologically include brain, lung, heart, liver, small and large intestine, abdominal vasculature, and kidneys (data not shown). $D B H-E T_{B} ; E T_{B}{ }^{s / s l}$ rats live well into adulthood, and both males and females are fertile.

$D B H-E T_{B} ; E T_{B}{ }^{s l} / s l$ rats are $E T_{B}$-deficient. Nontransgenic $E T_{B}{ }^{s l / s l}$ rats lack functional $E T_{\mathrm{B}}$. They exhibit coat color spotting and distal intestinal aganglionosis which leads to death shortly after birth (16). In contrast, $\mathrm{DBH}$ $E T_{B} ; E T_{B}{ }^{s l} / s l$ rats exhibit normal intestinal development while maintaining (on a nonalbino genetic background) the coat color spotting characteristic of nontransgenic $E T_{B}{ }^{s l / s l}$ rats (23). To show that adult $D B H-E T_{B} ; E T_{B}{ }^{s l / s l}$ rats are $\mathrm{ET}_{\mathrm{B}}$ deficient, we performed in situ hybridization for $E T_{B}$ mRNA on a variety of tissues from wild-type and $D B H-E T_{B} ; E T_{B}{ }^{s l} / s l$ rats. Figure 1 demonstrates the absence of detectable $E T_{B}$ mRNA in the glomeruli and associated renal tubules and vasculature in the $D B H-E T_{B} ; E T_{B}{ }^{s / s l}$ kidney (Figure 1, c and d) compared with wild-type kidney (Figure 1, a and b). Signal in $D B H-E T_{B} ; E T_{B}{ }^{s / s l}$ is not significantly increased over background. The probe corresponds to the fragment of the $E T_{B}$ mRNA that is delet- ed in the spotting lethal $E T_{B}$ mRNA; hence, it will not detect the nonfunctional $E T_{B}{ }^{s l}$ transcript. This probe for $E T_{B}$ mRNA does not cross-detect $E T_{A}$ mRNA (23).

To show that adult $D B H-E T_{B} ; E T_{B}{ }^{s l / s l}$ rats are functionally $\mathrm{ET}_{\mathrm{B}}$ deficient, we examined vascular responses to acute ET-1 injection (Figure 2). DBH-ET $T_{B} E T_{B}{ }^{s l} / s l$ rats show a significantly different response to exogenous ET-1 compared with $E T_{B}{ }^{+/+}$rats $(P<0.001$ by paired $t$ test). Acute injection of ET-1 into wild-type rats produces a transient vasodilatory response followed by a prolonged pressor response. The initial vasodilatory phase is well described as an $\mathrm{ET}_{\mathrm{B}}$-mediated response (27). Although this response, including the hypotensive phase, is clearly demonstrated in $D B H-E T_{B} ; E T_{B}{ }^{+/+}$rats after administration of $1 \mathrm{nmol} / \mathrm{kg}$ ET-1, it is completely absent in $D B H-E T_{B} ; E T_{B}{ }^{s l} / s l$ rats. Figure 2 shows the response of $D B H-E T_{B} ; E T_{B}{ }^{s / s l}$ rats fed a high-sodium diet for 3 weeks and treated with amiloride for 3 days before study. Although their baseline blood pressure was lower, their response to acute administration of ET-1 was identical to $D B H-E T_{B} ; E T_{B}{ }^{s l} / s l$ fed a normal diet before study (data not shown).

The DBH-ET $T_{B}$ transgene does not affect blood pressure. To show that the rescuing transgene per se has no effect on blood pressure, we measured blood pressure in nontransgenic $E T_{B}{ }^{+/+}$and $D B H-E T_{B} ; E T_{B}{ }^{+/+}$rats fed a high-sodium diet. No significant difference was observed between the 2 groups (mean arterial pressure $[\mathrm{MAP}]=107 \pm 2 \mathrm{mmHg}$

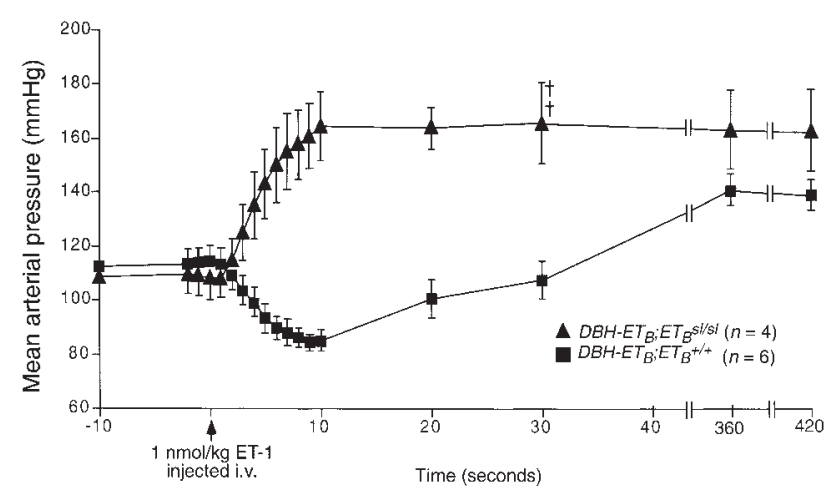

\section{Figure 2}

Arterial pressure response to exogenous ET-1 in $D B H-E T_{B} ; E T_{B}{ }^{s l / s l}$ and $D B H-E T_{B} ; E T_{B}^{+/+}$rats. Significant differences $(P<0.001$ by paired $t$ test $)$ in the arterial blood pressure responses to acute injection of ET-1, 1 $\mathrm{nmol} / \mathrm{kg}$ intravenously, are demonstrated in $D B H-E T_{B} ; E T_{B}^{+/+}$and $D B H$ $E T_{B} ; E T_{B}{ }^{s / s l}$ rats. Measurements were made under ketamine and xylazine anesthesia in the abdominal aorta via a catheter inserted through the femoral artery. ET-1 was given intravenously (i.v.) in the tail. $D B H$ $E T_{B} ; E T_{B}^{s / s l}$ rats were fed a high-sodium diet for 3 weeks and were treated with amiloride for 3 days before the study. Time of ET- 1 injection is indicated by the arrow at the bottom of the figure. $E T_{B}^{+/+}$rats show the prototypic transient depressor response followed by sustained pressor response. The depressor response is absent in $D B H-E T_{B} ; E T_{B}^{s / / s l}$ rats. Similar absence of the transient depressor response was also observed in $D B H-E T_{B} ; E T_{B}{ }^{s / s}$ fed a normal sodium diet before study (data not shown). Crosses indicate $D B H-E T_{B} ; E T_{B}{ }^{s / s l}$ animals that died during the study. Both of the 2 surviving $D B H-E T_{B} ; E T_{B}{ }^{s / s l}$ animals developed retinal hemorrhages seconds after ET-1 injection. 

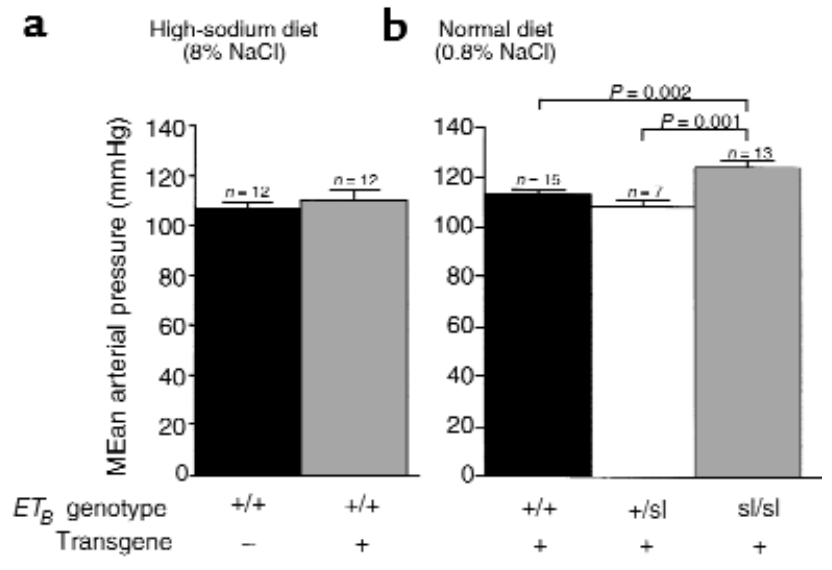

\section{Figure 3}

Effect of $D B H-E T_{B}$ transgene and $\mathrm{ET}_{\mathrm{B}}$-genotype on MAP in rats. The $D B H-E T_{B}$ transgene has no effect on arterial blood pressure (a). MAP is shown in nontransgenic $E T_{B}^{+/+}(107 \pm 2 \mathrm{mmHg})$ and $D B H-E T_{B} ; E T_{B}^{+/+}$ $(110 \pm 3 \mathrm{mmHg})$ rats. All rats were maintained on a high-sodium diet $(8 \% \mathrm{NaCl})$ for at least 3 weeks before measurement and were 8 - to 10 week-old males. No difference in pulse rate was found (data not shown). (b) MAP of DBH-ET $; E T_{B}^{+/+}, D B H-E T_{B} ; E T_{B}^{+/ s l}$, and $D B H-E T_{B} ; E T_{B}{ }^{s l / s l}$ rats on a normal rodent chow diet reveals a significant elevation in MAP in $D B H$ $E T_{B} ; E T_{B}^{s / s l}(124 \pm 3 \mathrm{mmHg})$ compared with $D B H-E T_{B} ; E T_{B}^{+/+}(113 \pm 2$ $\mathrm{mmHg})$ and $D B H-E T_{B} ; E T_{B}{ }^{+/ s l}(106 \pm 3 \mathrm{mmHg})$ rats. Systolic and diastolic pressures in $D B H-E T_{B} ; E T_{B}^{s / s l}$ rats were increased. No significant difference in pulse rate was observed (data not shown). All rats were fed a normal rodent chow $(0.8 \% \mathrm{NaCl})$ and were 8 - to 10 -week-old males. Blood pressure was measured in acclimated, conscious, unrestrained rats via a femoral artery catheter 24 hours after surgery.

[ $n=12]$ vs. $110 \pm 3 \mathrm{mmHg}[n=12]$ ) (Figure 3a).

$D B H-E T_{B} ; E T_{B}{ }^{s l s l}$ rats are bypertensive on a normal sodium diet. We examined the effect of $E T_{B}$ genotype on blood pressure in rats fed a normal chow $\operatorname{diet}(0.8 \% \mathrm{NaCl})$ and observed no difference between the $D B H-E T_{B} ; E T_{B}{ }^{+/}$ $(\mathrm{MAP}=113 \pm 2 \mathrm{mmHg} ; n=15)$ and $D B H-E T_{B} ; E T_{B}{ }^{+/ s l}$ ( $\mathrm{MAP}=106 \pm 3 \mathrm{mmHg} ; n=7)$ rats. A significant difference was observed between $D B H-E T_{B} ; E T_{B}^{+/+}, D B H$ $E T_{B} ; E T_{B}{ }^{+/ s l}$, and $D B H-E T_{B} ; E T_{B}^{s l / s l}$ rats (MAP $=124 \pm 3$ $\mathrm{mmHg} ; P<0.001$ by ANOVA) (Figure $3 \mathrm{~b}$ ). Both systolic and diastolic pressures were significantly increased in $D B H-E T_{B} ; E T_{B}{ }^{s / s l}$ rats. No significant difference in pulse rate was observed (data not shown).

The bypertension in $D B H-E T_{B} ; E T_{B}{ }^{s l / s l}$ rats is salt sensitive. To determine the effect of dietary sodium on blood pressure in $D B H-E T_{B} ; E T_{B}{ }^{s / s l}$ rats, we measured blood pressure in $D B H-E T_{B} ; E T_{B}^{+/+}$and $D B H-E T_{B} ; E T_{B}{ }^{s / s l}$ rats fed a sodium-deficient $\operatorname{diet}(0.008 \% \mathrm{NaCl})$ or a high-sodium diet $(8 \% \mathrm{NaCl})$. Figure 4 shows that $D B H-E T_{B} ; E T_{B}{ }^{s / s l}$ rats exhibit extreme salt-sensitive hypertension. On the sodium-deficient diet (Figure 4a), there was no significant difference in the MAP of $D B H-E T_{B} ; E T_{B}^{+/+}(120 \pm 2$ $\mathrm{mmHg} ; n=12)$ and $D B H-E T_{B} ; E T_{B}{ }^{l / s l}(127 \pm 4 \mathrm{mmHg} ; n$ $=10$ ) rats. However, on the high-sodium diet, both diastolic and systolic arterial pressures were significantly increased in $D B H-E T_{B} ; E T_{B}{ }^{s / s l}$ rats compared with rats on the sodium-deficient diet. The MAP in $D B H-E T_{B} ; E T_{B}{ }^{l / s l}$ rats on a high-sodium diet was $168 \pm 7 \mathrm{mmHg}(n=20$;
$P<0.001$ compared with $D B H-E T_{B} ; E T_{B}{ }^{s / s l}$ rats on a sodium-deficient diet). The blood pressure of $D B H$ $E T_{B}: E T_{B}{ }^{+/+}$rats was not affected by high dietary sodium $(\mathrm{MAP}=121 \pm 2 \mathrm{mmHg} ; n=20)$ (Figure 4b).

Hypertension in DBH-ET $T_{B ;} E T_{B}{ }^{s l / s l}$ rats is sustained and nonprogressive. We measured the MAP in $D B H-E T_{B} ; E T_{B} s / s l$ rats fed a high-sodium diet for 21-88 days. No significant trend in MAP was detected. By 3 weeks, the saltsensitive hypertension exhibited by $D B H-E T_{B} ; E T_{B}{ }^{s / s l}$ rats is maximal, and it is maintained at this level, at least over the next 9 weeks (data not shown).

Hypertension in $D B H-E T_{B} ; E T_{B}{ }^{s / s l}$ rats is responsive to $E N a C$ inbibition. To test whether this salt-sensitive hypertension is the result of increased activity of the renal $\mathrm{ENaC}$, we examined the effect of amiloride, at doses that produce specific inhibition of the $\mathrm{ENaC}$ in vivo (28), on blood pressure in hypertensive $D B H-E T_{B} ; E T_{B}^{s l / s l}$ rats. Figure $4 \mathrm{~b}$ illustrates the significant reduction in MAP in $D B H-E T_{B}: E T_{B}{ }^{l / s l}$ rats treated with $3 \mathrm{mg} / \mathrm{kg}$ amiloride intraperitoneally for 3 days before blood pressure measurement ( $168 \pm 7$ vs. 124 $\pm 5 \mathrm{mmHg} ; P<0.001$ ). We detected no significant difference between MAP of salt-fed $D B H-E T_{B} ; E T_{B}^{\text {sl/sl }}$ rats treated with amiloride $(n=12)$, salt-deprived $D B H-E T_{B} ; E T_{B}^{s l / s l}$ rats $(n=10)$, and salt-fed $D B H-E T_{B}: E T_{B}{ }^{+/+}(n=20)$ rats. Amiloride treatment had no effect on the MAP in salt-fed $D B H-E T_{B} ; E T_{B}{ }^{+/+}$rats $(121 \pm 2$ vs. $120 \pm 3 \mathrm{mmHg})$.

$D B H-E T_{B} ; E T_{B}^{s l s l}$ rats exhibit increased circulating ET-1. Endothelial $\mathrm{ET}_{\mathrm{B}}$ may have an important role in clearing circulating ET-1. To investigate whether $D B H$ $E T_{B} ; E T_{B}{ }^{s / s l}$ rats exhibit increased circulating ET-1, we measured plasma ET-1 levels in $D B H-E T_{B} ; E T_{B}{ }^{s / s l}$ rats fed either a high-salt or a sodium-deficient diet. $D B H^{-}$ $E T_{B} ; E T_{B}{ }^{s / s l}$ rats exhibit increased circulating levels of ET-1 compared with $D B H-E T_{B} ; E T_{B}{ }^{+/+}$rats (Figure $5 a$ ). The circulating ET-1 levels in $D B H-E T_{B} ; E T_{B}^{+/+}$rats was not significantly affected by dietary sodium: $D B H$ $E T_{B} ; E T_{B}^{+/+}$rats on a low-sodium diet exhibited a circulating ET-1 level of $2.1 \pm 1.8 \mathrm{pg} / \mathrm{mL}(n=4)$ and $D B H-$ $E T_{B} ; E T_{B}^{+/+}$rats on a high-sodium diet exhibited a circulating ET-1 level of $4.4 \pm 1.4 \mathrm{pg} / \mathrm{mL}(n=6)$. The plasma ET-1 levels in $D B H-E T_{B}: E T_{B}{ }^{s l / s l}$ rats fed a sodium-deficient diet was $13.2 \pm 2.8 \mathrm{pg} / \mathrm{mL}(n=11)$, significantly elevated compared with $D B H-E T_{B} ; E T_{B}{ }^{+/+}$rats fed a sodium-deficient $\operatorname{diet}(P=0.04) . D B H-E T_{B}: E T_{B}{ }^{s l / s l}$ rats fed a high-sodium diet exhibited a plasma ET-1 level significantly elevated $(23.9 \pm 4.2 \mathrm{pg} / \mathrm{mL} ; n=8)$ compared with both $D B H-E T_{B} ; E T_{B}{ }^{+/+}$rats fed a high-sodium $\operatorname{diet}(P=0.002)$ and $D B H-E T_{B} ; E T_{B}{ }^{s l s l}$ rats fed a sodiumdeficient diet $(P=0.04)$. However, $\mathrm{ET}_{\mathrm{B}}$ genotype, but not diet, was a significant independent variable affecting plasma ET-1 level $(P<0.001)$, and there was no interaction of diet and genotype by 2 -way ANOVA. To investigate the extent to which activation of $\mathrm{ET}_{\mathrm{A}}$ contributes to the hypertension observed in $\mathrm{ET}_{\mathrm{B}}$-deficient rats, we acutely treated $D B H-E T_{B} ; E T_{B}^{+/+}$and $D B H$ $E T_{B} ; E T_{B}{ }^{s / s l}$ rats fed a high-sodium diet with $10 \mathrm{mg} / \mathrm{kg}$ FR139317, a selective $\mathrm{ET}_{\mathrm{A}}$ antagonist. Figure $5 \mathrm{~b}$ shows that $D B H-E T_{B} ; E T_{B}{ }^{l l / s l}$ rats have a significantly increased response $(-15 \pm 5 \mathrm{mmHg}$ in $\triangle \mathrm{MAP})$ to FR139317 com- 


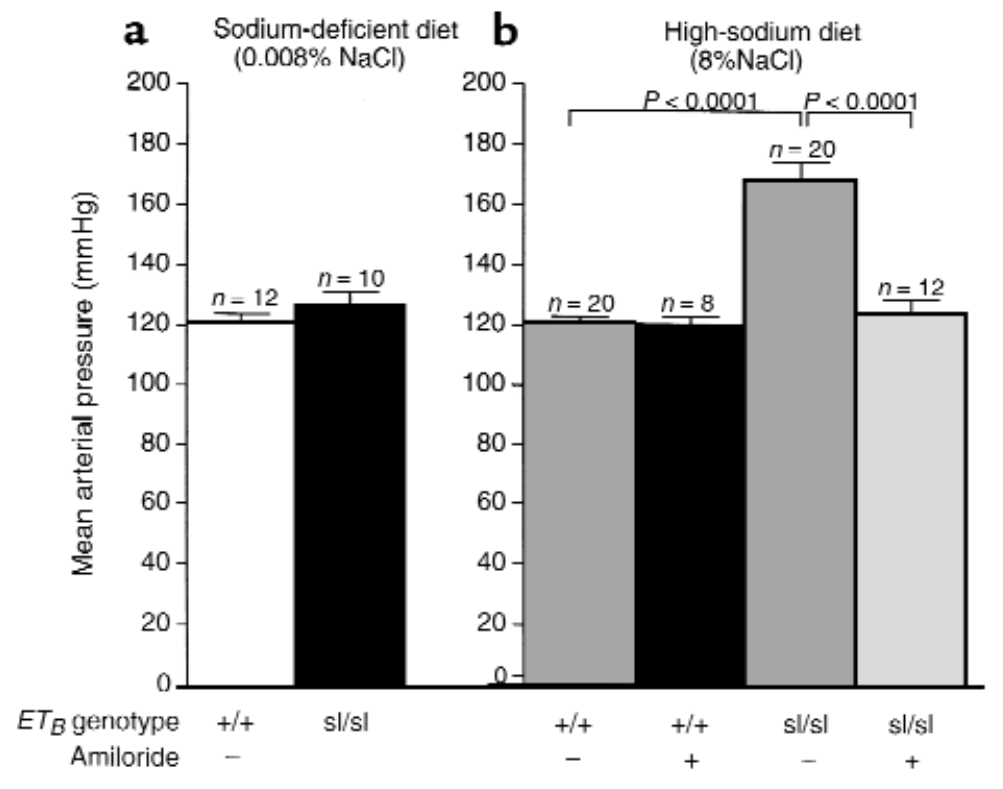

\section{Figure 4}

Effect of dietary sodium and amiloride on blood pressure in $D B H-E T_{B} ; E T_{B}^{+/+}$and $D B H-E T_{B} ; E T_{B}{ }^{s / s l}$ rats. MAP in $D B H$ $E T_{B} ; E T_{B}{ }^{s / s l}$ rats $(127 \pm 4 \mathrm{mmHg})$ was not significantly different from that of $D B H-E T_{B} ; E T_{B}{ }^{+/}$rats $(120 \pm 2 \mathrm{mmHg})$ on a sodium-deficient diet (a). However, on a high-sodium diet, $D B H-E T_{B} ; E T_{B}{ }^{s / s l}$ rats exhibit severe hypertension $(\mathrm{MAP}=168 \pm 7 \mathrm{mmHg})$. This is a statistically significant increase over $D B H-E T_{B} ; E T_{B}^{s / s l}$ rats on a sodium-deficient $\operatorname{diet}(\mathbf{a} ; P<0.001)$ and $D B H-E T_{B} ; E T_{B}^{+/+}$rats on a highsodium diet (first bar $\mathbf{b} ; P<0.001$ ). $D B H-E T_{B} ; E T_{B}{ }^{+/+}$rats exhibited no increase in blood pressure in response to increased dietary sodium. $\mathbf{b}$ illustrates the dramatic blood pressure response to amiloride in salt-fed $D B H-E T_{B} ; E T_{B}{ }^{s / s l}$ rats. The MAP in amiloride-treated, $D B H-E T_{B} ; E T_{B}^{s / s l}$ rats on a high-sodium diet was not significantly different from the MAP in $D B H-E T_{B} ; E T_{B}{ }^{s / s l}$ rats fed a sodium-deficient diet $(124 \pm 5$ vs. $127 \pm 4 \mathrm{mmHg})$. $D B H-E T_{B} ; E T_{B}{ }^{+/+}$rats showed no response to amiloride treatment. All animals were maintained on the designated diet for 3 weeks before study and were 8- to 10-week old males. pared with $D B H-E T_{B} ; E T_{B}{ }^{+/+}$rats $(-3 \pm 2 \mathrm{mmHg}$ in MAP; $P=0.01)$. The effect of acute $\mathrm{ET}_{\mathrm{A}}$ blockade was relatively small and did not normalize MAP in salt-fed $D B H-E T_{B} ; E T_{B}{ }^{s l} / s l$ rats.

Salt-fed $D B H-E T_{B} ; E T_{B}{ }^{s l} / s l$ rats exhibit appropriate downregulation of the renin-angiotensin-aldosterone system. We investigated whether increased activity of the reninangiotensin-aldosterone system (RAS) is involved in the salt-sensitive hypertension observed in $D B H-E T_{B} ; E T_{B} s / s l$ rats. We measured circulating aldosterone and renin activity in (nontransgenic and transgenic) $E T_{B}{ }^{+/+}$and $D B H-E T_{B} ; E T_{B}{ }^{s l} / s l$ rats. Although we were able to detect significant elevations in renin activity and aldosterone in $D B H-E T_{B} ; E T_{B}^{+/+}$or $D B H-E T_{B} ; E T_{B}{ }^{s / s l}$ rats fed a sodiumdeficient diet compared with rats fed a high-sodium diet, we detected no significant difference in aldosterone $(\mathrm{A})$ or renin activity $(\mathrm{R})$ levels between $\mathrm{DBH}$ $E T_{B} ; E T_{B}^{+/+}(\mathrm{A}: 11 \pm 7 \mathrm{ng} / \mathrm{dL}[n=5] ; \mathrm{R}: 161 \pm 99 \mathrm{ng} / \mathrm{dL}[n$ $=4]), D B H-E T_{B} ; E T_{B}{ }^{+/ s l}(\mathrm{~A}: 8 \pm 1 \mathrm{ng} / \mathrm{dL}[n=7] ; \mathrm{R}: 99 \pm 37$ $\mathrm{ng} / \mathrm{dL}[n=8])$, and $D B H-E T_{B} ; E T_{B} s / s l(\mathrm{~A}: 7 \pm 2 \mathrm{ng} / \mathrm{dL}[n=$ 8]; R: $25 \pm 3 \mathrm{ng} / \mathrm{dL}[n=8])$ rats on the high-sodium diet.

Serum electrolytes, blood chemistries, arterial blood $\mathrm{pH}$ and blood gases, and hemoglobin concentrations were normal and not significantly different between salt-fed $E T_{B}{ }^{+/+}$(transgenic or nontransgenic) rats and $D B H-E T_{B} ; E T_{B}{ }^{s l} / s l$ rats (Table 1$)$. We examined circulating epinephrine and norepinephrine levels in salt-fed rats. Again, no significant difference in epinephrine (E) or norepinephrine $(\mathrm{N})$ levels were detected between nontransgenic $E T_{B}{ }^{+/+}(\mathrm{E}: 674 \pm 19 \mathrm{pg} / \mathrm{mL}[n=3] ; \mathrm{N}: 603 \pm$ $366 \mathrm{pg} / \mathrm{mL}[n=3]), D B H-E T_{B} ; E T_{B}{ }^{+/+}(\mathrm{E}: 514 \pm 207$ $\mathrm{pg} / \mathrm{mL}[n=6] ; \mathrm{N}: 410 \pm 126 \mathrm{pg} / \mathrm{mL}[n=3])$, and $D B H-$ $E T_{B} ; E T_{B}{ }^{s / s l}$ rats $(\mathrm{E}: 808 \pm 116 \mathrm{pg} / \mathrm{mL}[n=5] ; \mathrm{N}: 601 \pm$ $230 \mathrm{pg} / \mathrm{mL}[n=2])$. We also examined circulating corticosterone levels in these rats. No significant difference was observed between nontransgenic $E T_{B}{ }^{+/+}(32 \pm 9$ $\mathrm{pg} / \mathrm{mL} ; n=3), D B H-E T_{B} ; E T_{B}{ }^{++}$or $E T_{B}{ }^{+/ s l}(22 \pm 3 \mathrm{pg} / \mathrm{mL}$; $n=9)$, and $D B H-E T_{B} ; E T_{B}{ }^{s l / s l}(28 \pm 2 \mathrm{pg} / \mathrm{mL} ; n=2)$ rats.
Further, $D B H-E T_{B} ; E T_{B}{ }^{+/+}$and $D B H-E T_{B} ; E T_{B}{ }^{s l / s l}$ rats fed a normal chow diet were treated acutely with $30 \mathrm{mg} / \mathrm{kg}$ captopril by intra-arterial injection. No difference was observed in response to captopril between $\mathrm{DBH}$ $E T_{B} ; E T_{B}^{+/+}(-5 \pm 1 \mathrm{mmHg}$ in $\triangle \mathrm{MAP} ; n=9)$ and $D B H$ $E T_{B} ; E T_{B}{ }^{s l / s l}(-2 \pm 4 \mathrm{mmHg}$ in $\triangle \mathrm{MAP} ; n=5)$ rats.

Hypertensive $D B H-E T_{B} ; E T_{B}{ }^{s l} / s l$ rats do not exhibit decreased vascular response to NOS and cyclooxygenase inbibition. Because $\mathrm{ET}_{\mathrm{B}}$ activation on the vascular endothelial cells results in increased production of $\mathrm{NO}$ and prostacyclin, we undertook experiments to investigate the extent to which downregulation of $\mathrm{NO}$ and prostacyclin production by the endothelial cells contributes to the hypertension observed in $D B H-E T_{B} ; E T_{B}{ }^{s l} / s l$ rats. We examined the effect of acute injection of $23 \mathrm{mg} / \mathrm{kg}$ L-NAME together with $5 \mathrm{mg} / \mathrm{kg}$ indomethacin on blood pressure in normal chow-fed $D B H-E T_{B} ; E T_{B}{ }^{+/}$and $D B H$ $E T_{B} ; E T_{B}{ }^{s l} / s l$ rats. We found no significant difference in the response to L-NAME and indomethacin between $D B H-E T_{B} ; E T_{B}^{+/+}(+41 \pm 5 \mathrm{mmHg}$ in $\triangle \mathrm{MAP} ; n=6)$ and $D B H-E T_{B} ; E T_{B}{ }^{s / s l}(+51 \pm 5 \mathrm{mmHg}$ in $\Delta \mathrm{MAP} ; n=7)$ rats.

\section{Discussion}

Creation of $E T_{B}$-deficient adult rats. We created adult rats deficient in $\mathrm{ET}_{\mathrm{B}}$ by transgenically expressing $E T_{B}$ in a tissuespecific manner in the $E T_{B}$-null spotting lethal rat. The resulting $D B H-E T_{B} ; E T_{B}^{s l / s l}$ rats express $E T_{B}$ only under the transcriptional control a $5.8-\mathrm{kb}$ fragment of the human $D B H$ promotor. They express $E T_{B}$ in adrenergic tissues but lack $\mathrm{ET}_{\mathrm{B}}$ in most sites where $\mathrm{ET}_{\mathrm{B}}$ is normally expressed. In a previous study, we performed in situ hybridization for $E T_{B}$ mRNA at embryonic days $11.5,13.5$, and 15.5 . We demonstrated that the transgene is expressed in a limited, tissue-specific manner during development and that the probe does not detect the abnormal $E T_{B}{ }^{s l}$ transcript or $E T_{A}$ mRNA (23). In the present study, we use the same probe for $E T_{B}$ mRNA in situ hybridization in adult $D B H$ $E T_{B} ; E T_{B}^{s l / s l}$ rats. We demonstrate that the adult $D B H-$ 
$E T_{B} E T_{B}^{s l / s l}$ rats are $E T_{B}$ deficient in the kidney (Figure 1). In addition, we demonstrate that $D B H-E T_{B} ; E T_{B}{ }^{\text {sl/sl }}$ rats are functionally $E T_{B}$ deficient in their response to exogenous intravenous ET-1 (Figure 2). The complete absence of the transient vasodepressor response to exogenous ET-1 administration in $D B H-E T_{B} ; E T_{B}{ }^{s / s l}$ rats confirms that they lack functional endothelial $\mathrm{ET}_{\mathrm{B}}$.

Importantly, we did not detect a physiologically relevant effect of the $D B H-E T_{B}$ transgene. $D B H-E T_{B} ; E T_{B}{ }^{+/+}$ rats were indistinguishable from nontransgenic $E T_{B}^{+/+}$ rats in arterial blood pressure, pulse rate, blood chemistries, arterial blood gases, circulating renin activity, and plasma aldosterone, corticosterone, and catecholamines concentrations (Figure $3 \mathrm{a}$ and Table 1 ).

Hypertension in $D B H-E T_{B} ; E T_{B}{ }^{\text {sl/sl }}$ rats is due to inappropriate activity of the $E N a C$. Although $D B H-E T_{B} ; E T_{B}{ }^{s l} / s l$ rats exhibit severe hypertension when fed a high-sodium diet, they exhibit a normal arterial blood pressure when placed on a sodium-deficient diet. That is, the hypertension is salt dependent. We found no evidence that hypertension in $D B H-E T_{B} ; E T_{B}{ }^{s l} / s l$ rats results from inappropriate regulation of RAS. Renin activity and aldosterone levels were appropriately low in salt-fed $D B H-E T_{B} ; E T_{B}{ }^{s l / s l}$ rats, and they were not significantly different from those found in salt-fed $D B H-E T_{B} ; E T_{B}{ }^{+/+}$rats. Further, $D B H-E T_{B} ; E T_{B}{ }^{s l / s l}$ rats showed a normal response to acute treatment with captopril. However, salt-fed $D B H-E T_{B} ; E T_{B}{ }^{s l s l}$ rats respond dramatically to amiloride at doses that specifically block the activity of $\mathrm{ENaC}$ (Figure 4). In contrast, we detected no response to amiloride in salt-fed $D B H-E T_{B} ; E T_{B}{ }^{+/+}$rats (Figure $4 \mathrm{~b}$ ). This is consistent with previous studies that show that amiloride has no effect on $\mathrm{ENaC}$ activity in normal animals on a high-sodium diet (29). $\mathrm{DBH}$ -
$E T_{B} ; E T_{B}{ }^{s / s l}$ rats, therefore, exhibit inappropriate activity of ENaC while consuming a high-sodium diet. Although the RAS is an important physiological regulator of $\mathrm{ENaC}$ activity, it appears that in $D B H-E T_{B} ; E T_{B}{ }^{s / s l}$ rats, $\mathrm{ENaC}$ activity is high in the absence of elevated RAS activity. Hypertension and abnormal ENaC activity occur in $D B H-E T_{B} ; E T_{B}{ }^{s l / s l}$ rats in the face of appropriately very low renin activity and aldosterone levels. The amiloride-sensitive $\mathrm{ENaC}$ plays a key role in sodium transport in the kidney. It constitutes the final limiting step for sodium reabsorption in the epithelium of the distal nephron. Inappropriate $\mathrm{ENaC}$ activity leads to increased renal sodium reabsorption and hypertension. This is demonstrated in humans with gain-of-function $\mathrm{ENaC}$ mutations producing Liddle's syndrome.

We examined other proposed $\mathrm{ET}_{\mathrm{B}}$-mediated depressor mechanisms to evaluate their role in hypertension in the $D B H-E T_{B} ; E T_{B}{ }^{s l / s l}$ rat. Because $\mathrm{ET}_{\mathrm{B}}$ activation leads to increased production of NO and prostacyclin in the endothelium, we looked for evidence that the hypertension observed in $D B H-E T_{B} ; E T_{B}{ }^{s l / s l}$ rats was the result of reduced production of these vasoactive compounds. If the hypertension is the result of decreased $\mathrm{NO}$ and prostacyclin production, $D B H-E T_{B} ; E T_{B}{ }^{s l / s l}$ rats might exhibit decreased acute responses to L-NAME and indomethacin. However, we found no difference between $D B H-E T_{B} ; E T_{B} s / s l$ and $D B H-E T_{B} ; E T_{B}^{+/+}$rats in their hypertensive response to acute treatment with $\mathrm{L}-$ NAME and indomethacin. These findings suggest that the basal activity of NOS and cyclooxygenase are not changed in $D B H-E T_{B} ; E T_{B}{ }^{s l} / s l$ rats and that it is unlikely that the hypertension observed is due to decreased basal production of $\mathrm{NO}$ and prostacyclin.
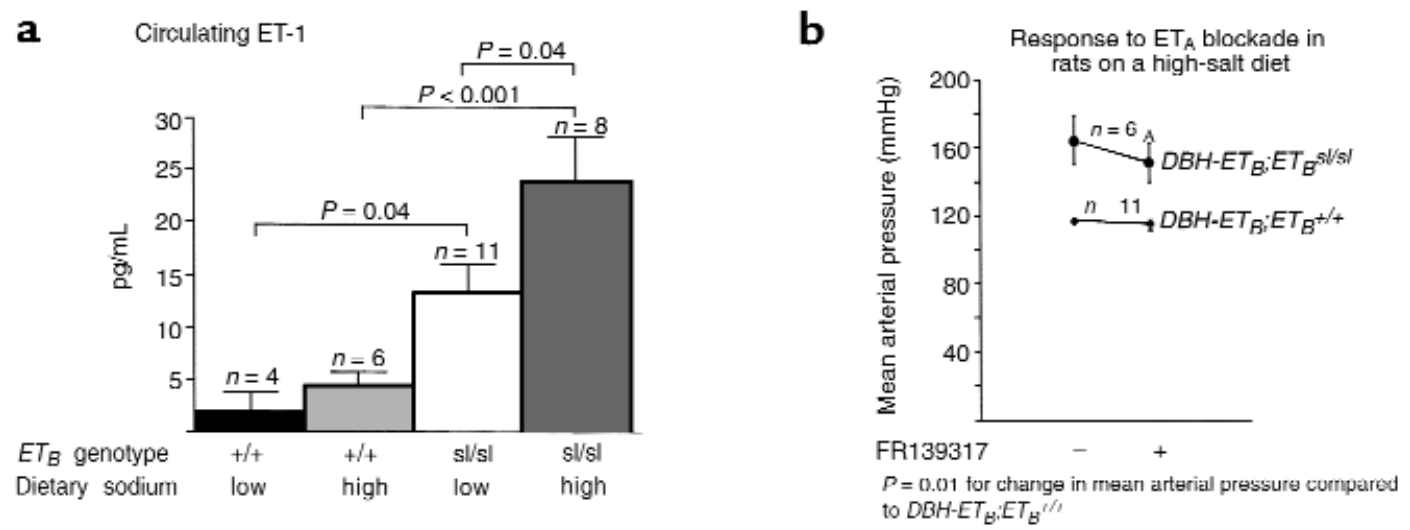

\section{Figure 5}

Circulating ET-1 levels and blood pressure response to $E T_{A}$ blockade in $D B H-E T_{B} ; E T_{B}^{+/+}$and $D B H-E T_{B} ; E T_{B}^{s l / s l}$ rats. $D B H-E T_{B} ; E T_{B}^{s l / s l}$ rats exhibited increased circulating ET-1 levels as measured by sandwich-type enzyme immunoassay (a). The level of dietary sodium did not significantly affect circulating $E T-1$ levels in $D B H-E T_{B} ; E T_{B}^{+/+}$rats. However, $E T_{B}$ genotype significantly affected plasma $E T-1$ levels. a shows a significant increase in plasma $E T-1$ in $D B H-E T_{B} ; E T_{B}{ }^{s / / s l}$ rats $(13.2 \pm 2.8 \mathrm{pg} / \mathrm{mL})$ compared with $D B H-E T_{B} ; E T_{B}^{+/+}$rats $(2.1 \pm 1.8 \mathrm{pg} / \mathrm{mL} ; P<0.02)$ on a sodium-deficient deficient diet. On a high-sodium diet, the plasma ET-1 level in $D B H-E T_{B} ; E T_{B}{ }^{s / / s l}$ rats $(23.9 \pm 4.2 \mathrm{pg} / \mathrm{mL})$ was also significantly increased compared with $D B H-E T_{B} ; E T_{B}{ }^{+/+}$rats $(4.4 \pm 1.4 \mathrm{pg} / \mathrm{ml} ; P<0.001)$. $D B H-E T_{B} ; E T_{B}{ }^{s / s l}$ rats on a high-sodium diet exhibited a significantly increased plasma $E T-1$ level compared with $D B H-E T_{B} ; E T_{B}{ }^{s / s l}$ rats on a sodium-deficient diet, although diet was not an independent variable affecting plasma ET-1 concentration by 2-way ANOVA. (b) $D B H-E T_{B} ; E T_{B}{ }^{s / s l}$ rats exhibit an increased acute depressor response to $E T_{A}$ blockade with FR139317 $\left(10 \mathrm{mg} / \mathrm{kg}\right.$, intra-arterially) compared with $E T_{B}^{+/+}$rats on a high-sodium diet. $D B H-E T_{B} ; E T_{B}^{s / / s l}$ rats are significantly hypertensive compared with $D B H-E T_{B} ; E T_{B}^{+/+}$rats before and after treatment with FR139317. However, the change in $M A P$ in $D B H-E T_{B} ; E T_{B}^{s / / s l}$ rats in response to FR139317 $(-15 \pm 5 \mathrm{mmHg})$ is significantly greater than in $D B H-E T_{B} ; E T_{B}^{+/+}$rats $\left(-3 \pm 2 \mathrm{mmHg} ;{ }^{A} P=0.01\right)$. 
Because endothelial $\mathrm{ET}_{\mathrm{B}}$ is thought to play a role as a clearance receptor for circulation ET-1, and because decreased clearance of circulating ET-1 may lead to increased activation of $\mathrm{ET}_{\mathrm{A}}$ and vasoconstriction, we examined both circulating ET-1 levels and responses to $E T_{\mathrm{A}}$ blockade in our rats. $D B H-E T_{B} ; E T_{B}{ }^{s l} / s l$ rats exhibit increased circulating ET-1 (Figure 5a). However, the circulating ET-1 level in $D B H-E T_{B} ; E T_{B}{ }^{s / s l}$ rats is significantly elevated both in rats fed a sodium-deficient diet and those fed a high-sodium diet. Although the level of dietary sodium did not detectably alter the plasma ET-1 level in the rats overall as judged by 2-way ANOVA $(P=$ $0.08)$, it may affect circulating ET-1 levels in $\mathrm{DBH}$ $E T_{B} ; E T_{B}{ }^{s / s l}$ rats $(P=0.04$ by Student's $t$ test). Possible explanations for this observation include: (a) $\mathrm{ET}_{\mathrm{B}}$ activation normally suppresses ET-1 production in the presence of high sodium intake; (b) $\mathrm{ET}_{\mathrm{B}}$ in its role as a clearance receptor obscures increased production of ET-1 in response to high sodium intake; or (c) hypertension in $D B H-E T_{B} ; E T_{B}{ }^{s / s l}$ rats on a high-sodium diet leads to a secondary increase in ET-1 production. The present study does not enable us to distinguish these possibilities.

We also found that $D B H-E T_{B} ; E T_{B}{ }^{s l / s l}$ rats exhibit increased hypotensive responses to $\mathrm{ET}_{\mathrm{A}}$ blockade. This suggests that exaggerated $\mathrm{ET}_{\mathrm{A}}$ activation may occur in $D B H-E T_{B} ; E T_{B}{ }^{s / s l}$ rats. However, the baseline blood pressure of the $D B H-E T_{B} ; E T_{B}{ }^{s l / s l}$ rats subjected to $E T_{A}$ blockade was still significantly higher than that of the $D B H-E T_{B} ; E T_{B}^{+/+}$ rats. It may be that these rats are, as in hypertensive humans and several other animal models of hypertension, more responsive to $\mathrm{ET}_{\mathrm{A}}$ blockade than are normotensive rats, perhaps owing to secondary vascular damage.

We cannot exclude the possibility that increased activation renal tubule $\mathrm{ET}_{\mathrm{A}}$ modulates $\mathrm{ENaC}$ activity in $D B H-E T_{B} ; E T_{B}{ }^{s / s l}$ rats, although we believe this is unlikely for several reasons. First, renal tubules express predominantly $\mathrm{ET}_{\mathrm{B}}$. Second, functional studies implicate $\mathrm{ET}_{\mathrm{B}}$ in mediating most ET-1 effects in the renal tubule (14). ET1 primarily inhibits sodium and water reabsorption by the cortical collecting tubule through activation of $\mathrm{ET}_{\mathrm{B}}$ on the basolateral membrane. Urinary sodium is increased in response to ET-1 in both the isolated perfused rat kidney and rats infused with subpressor doses of ET-1 (30). It is likely that at physiological levels, ET-1 acts through $\mathrm{ET}_{\mathrm{B}}$ to inhibit renal sodium reabsorption (31). Gallego and colleagues (1996), in patch-clamp studies using the A6 distal nephron cell line, found dosedependent and receptor-dependent effects of basolateral ET-1 on sodium transport. They found that low-dose ET-1 inhibits the ENaC through $\mathrm{ET}_{\mathrm{B}}$ activation, whereas high-dose (pressor dose) ET-1 increased ENaC sodium transport through $\mathrm{ET}_{\mathrm{A}}$ activation. However, while many studies implicate $\mathrm{ET}_{\mathrm{B}}$ in mediating diuresis and natriuresis at the renal tubule, the role of $\mathrm{ET}_{\mathrm{A}}$ in modulating intact renal tubular function remains obscure.

Finally, while the hypertension in salt-fed $D B H$ $E T_{B} ; E T_{B}{ }^{s / s l}$ rats is severe, it is not progressive. This suggests that although inappropriately increased $\mathrm{ENaC}$ activity continues, the rats are able eventually to com- pensate for this increased activity and balance sodium excretion with sodium intake. The mechanisms by which this is accomplished require further study.

Other models of $E T_{B}$ deficiency. Ohuchi et al. recently reported hypertension in mice with naturally occurring decreased expression of $E T_{B}$ (33). These mice express approximately one-eighth the normal level of $\mathrm{ET}_{\mathrm{B}}$. They found that the pressor response to acute treatment with BQ-788, an $\mathrm{ET}_{\mathrm{B}}$-specific antagonist, could be blocked by pretreatment with indomethacin. They suggest that ET elicits depressor effects through $\mathrm{ET}_{\mathrm{B}}$ under basal conditions, in part through tonic production of prostacyclin. In the present study, did not address this issue directly. We compared the response of $D B H-E T_{B} ; E T_{B}{ }^{s / s l}$ rats and $D B H-E T_{B} ; E T_{B}{ }^{+/+}$rats to combined cyclooxygenase and NOS inhibition, reasoning that if the hypertension in $D B H-E T_{B} ; E T_{B}{ }^{s l} / s l$ rats is the result of lack of either $\mathrm{NO}$ or prostacyclin, then $D B H-E T_{B} ; E T_{B}{ }^{s l / s l}$ rats would have a reduced response to L-NAME and indomethecin compared with $D B H-E T_{B} ; E T_{B}{ }^{+/+}$rats. We found that $D B H$ $E T_{B} ; E T_{B}{ }^{s l / s l}$ and $D B H-E T_{B} ; E T_{B}{ }^{+/+}$rats were equally responsive to acute treatment with L-NAME and indomethecin. Although the issue of salt sensitivity was not directly addressed by Ohuchi and colleagues, it may be that very low levels of $\mathrm{ET}_{\mathrm{B}}$ are adequate to allow normal downregulation of renal $\mathrm{ENaC}$ and that the mechanism of hypertension in mice with one-eighth the normal level of $E T_{B}$ is different from that in $D B H-E T_{B} ; E T_{B}{ }^{s l} / s l$ rats.

The role of the endothelin system in modulating renal sodium handling in wild-type animals. Evidence suggests that endothelins act strictly locally in fetal and adult mammals $(15,17,31,33)$. However, the response of the endothelin system within the kidney to alterations in sodium and water balance is controversial. Michel and colleagues examined plasma and urinary ET-1 levels in response to water deprivation and sodium loading in rats. They found that urinary ET-1 was significantly decreased in response to water deprivation. In addition, they detected an increase in renal ET-1 binding, although they did not investigate which receptor type was involved (35). They also found no change in rat urinary ET-1 (or renal ET-1 binding) in response to salt loading with $0.9 \% \mathrm{NaCl}$ drinking water (35). Firth and colleagues found no change in renal expression of ET- 1 in rats in response to salt restriction or diuretic treatment (36). More recently, Melo and colleagues (37) using an RIA on extracted tissue protein, detected an average $46 \%$ increase in renal ET1 in wild-type mice fed an $8 \% \mathrm{NaCl}$ diet compared with mice fed a sodium-deficient diet for 1 week. In contrast, Morita and colleagues (38) using an EIA on extracted tissue protein, detected an average $50 \%$ decrease in renal ET1 in wild-type mice fed an $8 \% \mathrm{NaCl}$ diet compared with mice fed a normal diet for 4 weeks. ET-1 extracted from kidneys may reflect renal production, but it may also reflect ET-1 produced elsewhere and bound in the kidney. More direct measurements of local ET-1 production in the kidney may help resolve these controversies.

Conclusions. Our data indicate that $D B H-E T_{B} ; E T_{B} s l / s l$ rats are functionally $\mathrm{ET}_{\mathrm{B}}$ deficient and, as a result, 
exhibit extreme salt-sensitive hypertension. The hypertension is salt dependent, i.e., the animals are normotensive on a sodium-deficient diet. Maintenance of the hypertension does not involve increased activity of the RAS, increased circulating catecholamines, or decreased production of the endothelial-derived vasodilators, $\mathrm{NO}$ and prostacyclin. Increased activity of the distal tubule $\mathrm{ENaC}$ occurs in $\mathrm{ET}_{\mathrm{B}}$-deficient rats fed a high-salt diet, as evidenced by the dramatic response of these rats to specific $\mathrm{ENaC}$ inhibition. Taken together, these results strongly suggest that $D B H-E T_{B} ; E T_{B} s l / s l$ rats exhibit systemic arterial hypertension as a result of abnormal high activity of $\mathrm{ENaC}$ on the renal collecting duct epithelium under high oral sodium intake.

This study of the $D B H-E T_{B} ; E T_{B}{ }^{s / s l}$ rat provides the first evidence for a physiologically important role of $\mathrm{ET}_{\mathrm{B}}$ in renal sodium handling in the whole animal. Our results suggests that in the distal nephron, the endothelin system (via epithelial $\mathrm{ET}_{\mathrm{B}}$ ) acts as a counterbalance to the RAS in regulation of the collecting duct $\mathrm{ENaC}$, i.e., the activation of epithelial $\mathrm{ET}_{\mathrm{B}}$ downregulates the $\mathrm{ENaC}$ under high salt intake (promoting natriuresis). Further, while $\mathrm{ET}_{\mathrm{B}}$ activation has many described effects, its dominant role in the intact rat is in regulating $\mathrm{ENaC}$ activity. In this manner, the endothelin system contributes substantially to the kidney's ability to control sodium excretion, and therefore, plays an important role in fluid-volume regulation.

\section{Acknowledgments}

We thank S. Dixon and C. Setiawan for their excellent technical assistance. M. Yanagisawa is an Investigator and T. Ohuchi is an Associate of the Howard Hughes Medical Institute (HHMI). C.E. Gariepy is a recipient of the HHMI Research Fellowship for Physicians. This work was supported in part by research grants from the Perot Family Foundation, the W.M. Keck Foundation, and the Tanabe Medical Frountier Conference.

1. Yanagisawa, M., et al. 1988. A novel potent vasoconstrictor peptide produced by vascular endothelial cells. Nature. 332:411-415.

2. Yanagisawa, M. 1994. The endothelin system: a new target for therapeutic intervention. Circulation. 89:1320-1322.

3. Xu, D., et al. 1994. ECE-1: a membrane-bound metalloprotease that catalyzes the proteolytic activation of big endothelin-1. Cell. 78:473-485.

4. Arai, H., Hori, S., Aramori, I., Ohkubo, H., and Nakanishi, S. 1990. Cloning and expression of a cDNA encoding an endothelin receptor Nature. 348:730-732.

5. Sakurai, T., et al. 1990. Cloning of a cDNA encoding a non-isopeptide-selective subtype of the endothelin receptor. Nature. 348:732-735.

6. Sudjarwo, S.A., Hori, M., and Karaki, H. 1992. Effect of endothelin-3 on cytosolic calcium level in vascular endothelium and on smooth muscle contraction. Eur. J. Pharmacol. 229:137-142.

7. Namiki, A., et al. 1992. Endothelin-1-and endothelin-3-induced vasorelaxation via common generation of endothelium-derived nitric oxide. Life Sci. 50:677-682.

8. Jouneaux, C., et al. 1994. Coupling of endothelin B receptors to the calcium pump and phospholipase $\mathrm{C}$ via $\mathrm{Gs}$ and $\mathrm{Gq}$ in rat liver. J. Biol. Chem. 269:1845-1851.

9. Schramek, H., et al. 1994. Endothelin-1 stimulates cytosolic phospholipase A2 in Chinese hamster ovary cells stably expressing human ETA or ETB receptor subtype. Biochem. Biophys. Res. Commun. 199:992-997.

10. Aramori, I., and Nakanishi, S. 1992. Coupling of two endothelin receptor subtypes to differing signal transduction in transfected Chinese hamster ovary cells. J. Biol. Chem. 267:12468-12474.

11. Koseki, C., Imai, M., Hirata, Y., Yanagisawa, M., and Masaki, T. 1989. Binding sites for endothelin-1 in rat tissues: an autoradiographic study. J. Cardiovasc. Pharmacol. 13:153-154.

12. Mosqueda-Garcia, R., Inagami, T., Appalsamy, M., Sugiwa, M., and Robertson, R. 1992. Endothelin as a neuropeptide: cardiovascular effects in the brainstem of normotensive rats. Circ. Res. 72:20.

13. Ruffolo,R., Jr. 1995. Endothelin receptors from the gene to the human. CRC Press Inc. Boca Raton, FL.

14. Clavell, A., Stingo, A., Margulies, K., Brandt, R., and Burnett, J. 1995. Role of endothelin receptor subtypes in the in vivo regulation of renal function. Am. J. Physiol. 268:F455-F460.

15. Baynash, A.G., et al. 1994. Interaction of endothelin-3 with endothelin$B$ receptor is essential for development of neural crest-derived melanocytes and enteric neurons: missense mutation of endothelin-3 gene in lethal spotting mice. Cell. 79:1277-1285.

16. Gariepy, C., Cass, D., and Yanagisawa, M. 1996. Null mutation of endothelin-B receptor gene in spotting lethal rats causes aganglionic megacolon and white coat color. Proc. Natl. Acad. Sci. USA. 93:867-872.

17. Hosoda, K., et al. 1994. Targeted and natural (piebald-lethal) mutations of endothelin-B receptor gene produce aganglionic megacolon associated with white-spotted coat color in mice. Cell. 79:1267-1276.

18. Attie, T., et al. 1995. Mutation of the endothelin-receptor B gene in Waardenberg-Hirschsprung disease. Hum. Mol. Genet. 4:2407-2409.

19. Auricchio, A., Casari, G., Staiano, A., and Ballabio, A. 1996. Endothelin$B$ receptor mutations in patients with isolated Hirschsprung disease from a non-inbred population. Hum. Mol. Genet. 5:351-354.

20. Puffenberger, E.G., et al. 1994. A missense mutation of the endothelinB receptor gene in multigenic Hirschsprung disease. Cell. 79:1257-1266.

21. Ikadai, H., Fujita, H., Agematsu, Y., and Imanichi, T. 1979. Observation of congenital aganglionosis rat (Hirschsprung's disease) and its genetical analysis. Congenital. Anom. 19:31-36.

22. Kapur, R.P., Yost, C., and Palmiter, R.D. 1992. A transgenic model for studying development of the enteric nervous system in normal and aganglionic mice. Development. 116:167-175.

23. Gariepy, C., Williams, S., Richardson, J., Hammer, R., and Yanagisawa, M. 1998. Transgenic expression of the endothelin-B receptor prevents congenital intestinal aganglionosis in a rat model of Hirschsprung disease. J. Clin. Invest. 102:1092-1101.

24. Clouthier, D., et al. 1998. Cranial and cardiac neural crest defects in endothelin-A receptor-deficient mice. Development. 125:813-824.

25. Suzuki, N., et al. 1990. Endothelin-3 concentration in human plasma: the increased concentrations in patients undergoing haemodialysis. Biochem. Biophys. Res. Commun. 169:809-815.

26. Tanimoto, K., et al. 1994. Angiotensin-deficient mice with hypotension. J. Biol. Chem. 269:31334-31337.

27. Webb, R., Navarete, A., and Ksander, G. 1995. Effects of the ETB-selecive antagonist IRL2500 in conscious spontaneously hypertensive and Wistar-Kyoto rats. J. Cardiovasc. Pharmacol. 26:S389-S392.

28. Dafnis, E., Kurtzman, N., and Sabatini, S. 1992. Effect of lithium and amiloride on collecting tubule transport enzymes. J. Pharmacol. Exp. Ther. 261:701-706.

29. Pacha, J., Frindt, G., Antonian, L., Silver, R., and Palmer, L. 1993. Regulation of Na channels of the rat cortical collecting tubule by aldosterone. J. Gen. Physiol. 102:25-42.

30. Harris, P., Zhuo, J., Mendelsohn, F., and Skinner, S. 1991. Haemodynamic and renal tubular effects of low doses of endothelin in anaesthetized rats. J. Physiol. (Lond). 422:25-39.

31. Kohan, D. 1997. Endothelins in the normal and diseased kidney. Am.J. Kidney Dis. 29:2-26.

32. Gallego, M., Ling, B. 1996. Regulation of amiloride-sensitive $\mathrm{Na}+$ channels by endothelin-1 in distal nephron cells. Am. J. Physiol. 271:F451-F460.

33. Ohuchi, T., et al. 1999. Elevation of blood pressure by genetic and pharmacological disruption of the ETB receptor in mice. Am. J. Physiol. 276:R1071-R1077.

34. Serneri, G., et al. 1995. Plasma endothelin and renal endothelin are two distinct systems involved in volume homeostasis. Am. J. Physiol. 37:H1829-H1837.

35. Michel, H., Backer, A., Meyer-Lehnert, H., Migas, I., and Kramer, H. 1993. Rat renal, aortic and pulmonary endothelin-1 receptors: effects of changes in sodium and water intake. Clin. Sci. 85:593-597.

36. Firth, J., Schricker, K., Ratcliffe, P., and Kurtz, A. 1995. Expression of endothelins 1 and 3 in the rat kidney. Am. J. Physiol. 269:F522-F528.

37. Melo, L., et al. 1998. Salt-sensitive hypertension in ANP knockout mice: potential role of abnormal plasma renin activity. Am. J. Physiol. 274:R255-R261.

38. Morita, H., et al. 1999. Response of blood pressure and catecholamine metabolism to high salt loading in endothelin-1 knockout mice. Hypertens. Res. 22:11-16. 